\title{
Physical activity in daily life in physically independent elderly participating in community-based exercise program
}

\author{
Atividade física na vida diária de idosos fisicamente independentes participantes de \\ programas de exercício físico oferecidos à comunidade \\ Nidia A. Hernandes ${ }^{1,2}$, Vanessa S. Probst ${ }^{1,2}$, Rubens A. Da Silva Jr. ${ }^{1,3}$, \\ Renata S. B. Januário ${ }^{1}$, Fabio Pitta ${ }^{2}$, Denilson C. Teixeira ${ }^{1}$
}

\begin{abstract}
Background: It is unclear whether participation in exercise programs specifically developed for elderly translates into a more active lifestyle. Objectives: To compare the objectively measured level of physical activity in daily life (PADL) between physically independent elderly who participate or do not participate in community-based exercise programs; and to evaluate which factors are associated with the higher level of PADL in these subjects. Method: 134 elderly participants in community-based exercise programs (PG) and 104 non-participants (NPG) had their level of PADL measured using pedometers during 7 days. Other measurements: 6-minute walking test (6MWT), incremental shuttle walking test (ISWT), muscle strength, flexibility and balance. Results: The PG had higher 1-week mean daily step count than NPG (8314 [IQR 5971-10060] vs. 6250 [IQR 4346-8207] steps/day, p<0.0001), as well as higher step count in any day of the week. There was a higher proportion of physically active subjects ( $\geq 8000$ steps/day) in PG than in NPG ( $37 \%$ vs. $16 \%$, respectively; $\mathrm{p}<0.001)$, as well as the proportion of sedentary subjects ( $<5000 \mathrm{steps} / \mathrm{day})$ ( $14 \%$ vs. $33 \%$, respectively; $\mathrm{p}<0.001)$. Participation in exercise programs, 6 MWT and ISWT explained a higher daily steps count (model $\mathrm{r}^{2}=0.56, \mathrm{p}<0.0001$ ). Conclusions: In physically independent elderly, a higher level of physical activity in daily life occurs in those who participate in community-based exercise programs, regardless of the weekday and including nonprogram days. Participation of elderly in community-based exercise programs should be more systematically available and encouraged due to its close link to higher activity levels and better exercise capacity.
\end{abstract}

Keywords: aged; motor activity; exercise; rehabilitation; regression analysis.

\section{HOW TO CITE THIS ARTICLE}

Hernandes NA, Probst VS, Da Silva Júnior RA, Januário RSB, Pitta F, Teixeira DC. Physical activity in daily life in physically independent elderly participating in community-based exercise program. Braz J Phys Ther. 2013 Jan-Feb; 17(1):57-63. http:// dx.doi.org/10.1590/S1413-35552012005000055

RESUMO | Contextualização: Não está claro se a participação em programas de exercício físico específicos para idosos se traduz em um estilo de vida mais ativo. Objetivos: Comparar o nível de atividade física na vida diária (AFVD) entre idosos fisicamente independentes (IFI) participantes e não participantes de programas de exercício oferecidos à comunidade e estudar os fatores associados ao maior nível de AFVD nesses indivíduos. Método: Cento e trinta e quatro IFI participantes de programas de exercício (GP) e 104 não participantes (GNP) tiveram seu nível de AFVD avaliado utilizando-se pedômetros durante sete dias. Outras avaliações foram teste de caminhada de 6 minutos (TC6min), incremental shuttle walking test (ISWT), força muscular, flexibilidade e equilíbrio. Resultados: O GP apresentou maior média de passos/dia em sete dias do que o GNP (mediana [IRQ25\%-75\%] 8314[5971-10060] vs 6250[43468207] passos/dia, $\mathrm{p}<0,0001$ ), bem como maior número de passos em qualquer dia da semana. Houve maior proporção de idosos fisicamente ativos ( $\geq 8000$ passos/dia) no GP em comparação com o GNP (37\% vs $16 \%$, respectivamente; $\mathrm{p}<0,001)$, assim como menor proporção de sedentários (<5000 passos/dia) ( $14 \%$ vs $33 \%$ respectivamente; $p<0,001)$. Um modelo de regressão linear múltipla mostrou que participação em programas, TC6min e ISWT explicaram uma maior média de passos/dia ( $\mathrm{r} 2=0,56, \mathrm{p}<0,0001)$. Conclusões: Em IFI, maior nível de AFVD ocorreu naqueles participantes de programas de exercício oferecidos à comunidade, mesmo analisando-se finais de semana e dias sem programa. A participação nesse tipo de programa deveria ser encorajada devido à sua relação com um estilo de vida mais ativo e melhor capacidade de exercício.

Palavras-chave: envelhecimento; atividade motora; exercício; reabilitação; análise de regressão.

\footnotetext{
${ }^{1}$ Research Centre in Health Sciences (CPCS), Centre of Biological and Health Sciences (CCBS), Universidade Norte do Paraná (UNOPAR), Londrina, PR, Brazil

${ }^{2}$ Laboratory of Research in Respiratory Physiotherapy (LFIP), Physical Therapy Department, Universidade Estadual de Londrina (UEL), Londrina, PR, Brazil

${ }^{3}$ Département des sciences de la santé, Programme Maîtrise ès sciences appliquées en physiothérapie, Université du Québec à Chicoutimi (UQAC), Canada

Received: 07/06/2012 Revised: 08/05/2012 Accepted: 08/07/2012
} 


\section{Introduction}

Aging is frequently associated with decrease of exercise capacity, muscle mass and strength and impaired balance. In addition, the impaired physical function frequently leads to decreasing in activities of daily living and, consequently, to loss of independence and poor quality of life $\mathrm{e}^{1,2}$. Physical inactivity relates to more deconditioning which may lead to a vicious circle of declining in physical function ${ }^{1}$. Moreover, low level of physical activity is a predictor of disability, admission to nursing homes, morbidity and mortality in older adults ${ }^{2-5}$.

It is well established that participation in regular and moderate physical activity can delay age-related functional declines. Elderly people can adapt physiologically to exercise training with gains in cardiorespiratory capacity, muscle function, static and dynamic balance and mobility, contributing to more independence in activities of daily living ${ }^{1,2,4-6}$. Despite all of these benefits, high proportions of older people in most countries have inactive lifestyle ${ }^{7}$.

Due to the population aging worldwide, increasing physical activity amongst older adults has become an international priority. Some strategies used by non- and governmental organizations are exercise programs developed at gyms, medical clinics or in the community. In spite of the physical benefits of the exercise, it remains unknown whether older adults who are engaged in an elderly specific program, such as community-based exercise programs, translate this participation in a more active lifestyle in daily life measured objectively with a motion sensor.

Therefore, we aimed to compare the objectively measured level of physical activity in daily life (PADL) between physically independent matched elderly who participate or do not participate in community-based exercise programs. In addition, we aimed to evaluate whether measurements of functional fitness, physical capacity and the participation in community-based exercise program are in fact associated with the level of physical activity in daily life in these elderly subjects.

\section{Method}

This cross-sectional study included 305 physically independent elderly, being 175 who participate in community-based exercise programs (participants group [PG]) and 130 elderly who were not participants of exercise programs (non-participants group [NPG]). NPG was recruited among individuals participating in a project which investigates the health conditions of the elderly in Londrina, Brazil, whereas PG was recruited from five community-based exercise programs in the same city. All subjects had their level of PADL, functional fitness and physical capacity evaluated. Data were collected from November 2008 to December 2010.

The inclusion criteria for the NPG were: age $\geq 60$ years, absence of severe and/or unstable disease which could limit the performance of PADL, as well as impair the performance of the other assessments and independence in daily life. Inclusion criteria for the PG group were the same listed above in addition to participating at least twice-weekly in a communitybased exercise program. Subjects were excluded if, for any reason, they did not complete seven days of objective assessment of PADL with the motion sensor, or misuse the assessment's diary.

\section{Ethics statement}

The study was approved by the Research Ethics Committee of the Universidade Norte do Paraná (UNOPAR n. PP000709) Londrina, PR, Brazil, and all participants gave written informed consent.

\section{Community-based exercise programs}

The community-based exercise programs included supervised lessons with 1 hour duration performed indoor twice a week (Monday and Wednesday or Tuesday and Thursday). In general, the lesson was structured as: 5 min of warm-up (e.g slow walking, callisthenic exercises, stretching), 20 to $25 \mathrm{~min}$ of moderate aerobic exercises (e.g. walking, dancing), 20 min of strength (e.g strength exercises involving flexors and extensors of knees, hip, shoulders, elbows and trunk using elastic bands and/or free weight) and balance exercises (e.g walking or standing on irregular surfaces, standing on one leg) and $5 \mathrm{~min}$ of cool down (e.g. stretching, relaxation techniques). Before and after the lessons, all participants had their arterial blood pressure and heart rate verified. All lessons were conducted by exercise health science students and supervised by a certified exercise health science professional.

\section{Monitoring of physical activity in daily life}

The level of PADL was objectively measured using a pedometer (Yamax SW-200 Digiwalker ${ }^{\circledR}$, Japan). Elderly were instructed to attach the pedometer to the right side of the waist as soon as waking up, to reset the device display and to wear it during, at least, 12 hours/day during one week. They were also strictly instructed to maintain their usual routine and to take out the device only for sleeping and taking baths. 
In addition, each day the subjects had to fill a daily log informing the time of starting and finishing the PADL measurement as well as register the number of steps counted at the end of the day. The average of one week of steps/day was used for analysis. Elderly who had a median of steps/day $<5000$ were classified as "sedentary" and those who had $\geq 8000$ steps/day in 5 or more days in a week were classified as "physically active" according to those indices proposed by Tudor-Locke and Bassett ${ }^{8}$ and TudorLocke et al. ${ }^{9}$ respectively.

\section{Physical capacity}

\section{Six minute walking test}

The six minute walking test (6MWT) was used to assess functional exercise capacity. Two tests were performed according to the American Thoracic Society guidelines ${ }^{10}$ and the best test was considered for analysis. The reference values used were those recommended by Troosters et al. ${ }^{11}$.

\section{Incremental shuttle walking test}

Maximal exercise capacity was evaluated using the incremental shuttle walking test (ISWT) ${ }^{12}$. Two tests were performed in a $10 \mathrm{~m}$ path where subjects should walk or run around according to the speed dictated by an audio signal; the speed increment was $0.17 \mathrm{~m} / \mathrm{s}$ each minute. The ISWT was interrupted in case of participants could not maintain the required speed due to dyspnea or fatigue; or if they failed to complete a shuttle in the time allowed for the second time. The best of the two tests was considered for analysis.

\section{Hand-grip strength}

Hand-grip strength was evaluated with manual dynamometry (Takei ${ }^{\circledR}$, Japan) using the protocol proposed by Vianna et al. ${ }^{13}$. The reference values were those proposed by Mathiowetz et al. ${ }^{14}$.

\section{Flexibility}

The flexibility of the lumbar spine and hamstrings were assessed by the sit-and-reach test. The test was performed according to the standards set by Lemmink et al. ${ }^{15}$ using a Wells bench.

\section{Functional fitness}

\section{0-s chair stand test}

The 30-s chair stand test is reliable for evaluating lower limb strength. The test was performed according to standardization proposed by Jones et al. ${ }^{16}$. It requires that subjects stand up and sit down from a chair with the arms crossed over the chest as fast as they can during 30 seconds. The score was the total number of stands executed during the test.

\section{Agility/dynamic balance test}

The test was proposed by the American Alliance for Health, Physical Education, Recreation \& Dance (AAHPERD) $)^{17}$ and consists of standing up from a chair and moving as fast as possible around two cones placed $1.50 \mathrm{~m}$ behind the chair and $1.80 \mathrm{~m}$ equidistant. The result of the test is given by the time spent to perform the task, in seconds.

\section{One leg balance test}

The test proposed by Greene et al. ${ }^{18}$ evaluates the static balance of individuals. The test consists in the longest time that the subject can stand on the dominant leg in a 30 -second window. The test is performed three times and the best test, i.e. the longest time, was considered for analysis.

\section{Self-reported comorbidities and medication}

A questionnaire was applied in order to investigate the presence of pre-diagnosed and non-limiting comorbidities such as cardiovascular, musculoskeletal and metabolic diseases, as well as the use of medication.

\section{Statistical analysis}

The normality in data distribution was verified by Shapiro-Wilk test. Data were expressed as median [interquartile range $25 \%-75 \%$ ] since data from most variables had non-normal distribution. Between-group (PG versus NPG) comparisons were performed using the Mann-Whitney test, except the 6MWT which was compared using the unpaired $t$ test. In case of categorical variables, Chi-square test was used. Simple correlations between level of PADL and variables of functional fitness and physical capacity were calculated using the Spearman correlation coefficient. A multiple linear regression model was built using the level of PADL (median of 7 days assessment) as dependent variable from the entire group (including both $\mathrm{PG}$ and NPG) and participation in community-based exercise programs and measurements of physical capacity (6MWT \% pred and ISWT) and functional fitness (30-sec chair stand, flexibility, agility and static balance) as independent variables, considering only those which presented statistical significance 
in the simple correlation analysis. As the level of PADL had an asymmetric distribution, a square root transformation was performed in order to the data to become normally distributed. Statistical significance was considered as $\mathrm{p}<0.05$.

A power calculation was performed based on the difference of level of PADL (in percentage) between a group of elderly which performed an exercise program and a control group observed by Meijer et al. ${ }^{1 .}$ Taking into consideration an alpha of 0.05 , a difference of $3 \pm 5 \%$ and a sample of 305

Table 1. Characteristics of study subjects.

\begin{tabular}{|c|c|c|c|}
\hline & $\begin{array}{c}\text { PG } \\
(n=134)\end{array}$ & $\begin{array}{c}\text { NPG } \\
(n=104)\end{array}$ & p-value \\
\hline Gender (M/ F) & $41 / 93$ & $32 / 72$ & 0.997 \\
\hline Age (yrs) & 68 [64-71] & 68 [64-71] & 0.933 \\
\hline BMI $\left(\mathrm{kg} \cdot \mathrm{m}^{-2}\right)$ & 26 [24-29] & $27[24-30]$ & 0.580 \\
\hline 6MWT (m) & 570 [523-614] & $540[480-579]$ & 0.002 \\
\hline 6MWT (\%pred) & $100[94-108]$ & 97 [88-106] & 0.004 \\
\hline ISWT (m) & $670[545-800]$ & $560[450-720]$ & 0.001 \\
\hline $\begin{array}{l}\text { Hand-grip strength } \\
(\mathrm{kgF})\end{array}$ & 27 [23-33] & $25[22-34]$ & 0.483 \\
\hline $\begin{array}{l}\text { 30-sec chair stand } \\
\text { (repetitions) }\end{array}$ & $13[12-15]$ & 12 [10-13] & 0.000 \\
\hline Flexibility (cm) & $23[13-30]$ & 23 [15-29] & 0.957 \\
\hline Agility (sec) & $22.8[21.0-24.9]$ & 24.5 [21.9-27.5] & 0.005 \\
\hline Static balance (sec) & $22.3[14.9-30.0]$ & $10.7[5.0-22.3]$ & 0.000 \\
\hline \multicolumn{4}{|c|}{$\begin{array}{l}\text { Data are expressed as median [interquartile range } 25 \%-75 \% \text { ]. } \\
\text { PG=group of elderly participants in community-based exercise } \\
\text { programs; NPG=group of elderly non-participants in community- } \\
\text { based exercise programs; BMI=body mass index; } 6 \mathrm{MWT}=\text { six } \\
\text { minute walking test; \%pred=percentage of the predicted values; } \\
\text { ISWT=incremental shuttle walking test. }\end{array}$} \\
\hline
\end{tabular}

Table 2. Proportion of self-reported comorbidities and use of medication in both groups.

\begin{tabular}{lccc}
\hline & PG $(\%)$ & NPG $(\%)$ & p-value \\
Cardiopathy & 20 & 23 & 0.548 \\
Arterial hypertension & 58 & 64 & 0.376 \\
$\begin{array}{l}\text { Peripheral vascular } \\
\text { disease }\end{array}$ & 23 & 39 & 0.011 \\
Diabetes mellitus & 17 & 33 & 0.007 \\
Osteoporosis & 17 & 18 & 0.861 \\
Osteoarthritis & 44 & 38 & 0.404 \\
Thyroid disease & 15 & 19 & 0.378 \\
Medication & 81 & 80 & 0.885 \\
\hline
\end{tabular}

$\mathrm{PG}=$ group of elderly participants in community-based exercise programs; NPG=group of elderly non-participants in community-based exercise programs. subjects, the probability is $100 \%$ that the study detects a difference between PG and NPG.

\section{Results}

From 305 physically independent elderly included in the present study, 41 subjects (23\%) in PG and 26 subjects (20\%) in NPG were excluded because they failed in completing the daily log and/or did not have seven days of PADL assessment. The characteristics of elderly in PG and NPG are described in Table 1. In both groups there was a higher prevalence of women (69\% in both groups); the median of age was similar in both groups and subjects had, in general, normal to overweight body mass index (Table 1). Among subjects in $\mathrm{PG}$, the median [interquartile range] time of participation in community-based exercise program was 12 [4-40] months.

\section{Self-reported comorbidities and medication}

There was no difference between groups in presence of cardiovascular and musculoskeletal diseases and use of medication continuously. However, in comparison to NPG, PG had lower proportion of elderly presenting diabetes mellitus (33\% vs. $17 \%, \mathrm{p}=0.007)$ and peripheral vascular disease ( $39 \%$ vs. $23 \%, \mathrm{p}=0.011)$ (Table 2$)$.

\section{Physical activity in daily life}

PG had a higher median of steps/day in comparison to NPG (8314 [5971-10060] steps/day vs. 6250 [4346-8207] steps/day, $\mathrm{p}<0.0001$, respectively) (Figure 1). Furthermore, 37\% of the elderly in PG were "physically active" against $16 \%$ in NPG, whereas $14 \%$ of PG were "sedentary" against 33\% in NPG ( $\mathrm{p}<0.001$, for both comparisons).

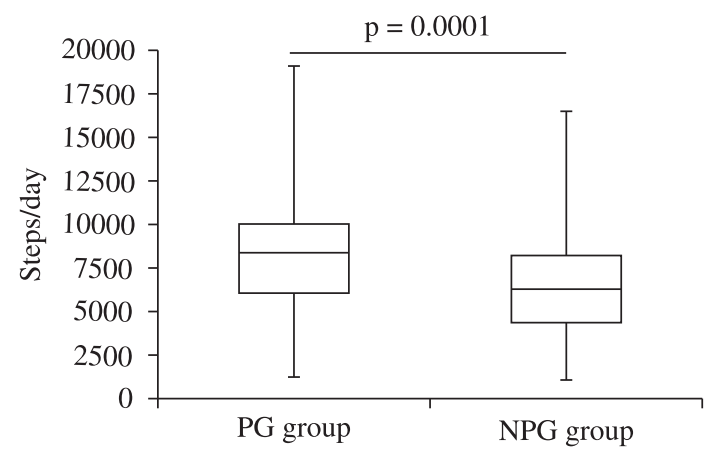

Figure 1. Comparison of the level of physical activity in daily life (average steps/day) in two groups of physically independent elderly: either participating (PG) or not participating (NPG) in community-based exercise programs. 
Table 3. Correlation between step count and exercise and functional capacity in both groups.

\begin{tabular}{lcc}
\hline & $\begin{array}{c}\text { Step count } \\
\text { PG }\end{array}$ & $\begin{array}{c}\text { Step count } \\
\text { NPG }\end{array}$ \\
6MWT (\%pred) & $0.43^{*}$ & $0.34^{*}$ \\
ISWT (m) & $0.45^{*}$ & $0.47^{*}$ \\
Hand-grip strength (kgF) & -0.11 & -0.10 \\
30-sec chair stand & $0.28^{*}$ & $0.30^{*}$ \\
(repetitions) & & \\
Flexibility (cm) & $0.20^{*}$ & 0.05 \\
Agility (sec) & $-0.34^{*}$ & $-0.52^{*}$ \\
Static balance (sec) & $0.24^{*}$ & $0.21^{*}$ \\
\hline
\end{tabular}

$\mathrm{PG}=$ group of elderly participants in community-based exercise programs; NPG=group of elderly non-participants in community-based exercise programs; 6MWT=six minute walking test, ISWT=incremental shuttle walking test.

In PG, the median of steps/day in exercise program days was similar to the median in non-exercise program days (8567 [6244-11163] steps/day vs. 8385 [5905-10932] steps/day, $\mathrm{p}>0.05$, respectively). Sunday (6045 [3526-8624] steps/day) was the most inactive day $(\mathrm{p}<0.05$ against median steps/day of exercise and non-exercise program days and against Saturday). The median of steps/day during weekdays in NPG was also higher than the weekend; however, in this group, Saturday was as inactive as Sunday (5236 [3595-8309] vs. 4576 [2791-7170], p>0.05, respectively). When comparing PG and NPG concerning the median of steps/day in the different days of the week, PG had higher step count in all of them, including the most inactive days in both groups ( $\mathrm{p}<0.02$ for all).

Statistical significant correlations were observed between variables of functional fitness and physical capacity and median steps/day in PG and NPG (Table 3). A multiple linear regression model was built and demonstrated that the level of PADL of healthy elderly in general was associated with participation in community-based exercise programs (partial correlation $[\mathrm{r}]=0.65)$, 6MWT (\% pred) $(\mathrm{r}=0.65)$ and ISWT $(\mathrm{r}=0.47, \mathrm{p}<0.0001$ for all $)$ $\left(\mathrm{r}^{2}=0.56, \mathrm{p}<0.0001\right)$.

\section{Functional fitness and physical capacity}

Physically independent elderly in PG had a better functional and maximal exercise capacity, lower limb muscle force, agility and static balance in comparison to NPG. In contrast, elderly in both groups had similar flexibility and hand-grip strength (Table 1).

\section{Discussion}

The present study demonstrated that physically independent elderly who are participants of community-based exercise programs are more physically active in daily life than those elderly who are not participants. Moreover, the level of physical activity in daily life in physically independent elderly was largely explained by participation in exercise programs and better maximal and functional exercise capacity.

In contrast to our findings, Meijer et al. ${ }^{1}$ did not find difference in the level of PADL objectively measured with a triaxial accelerometer in healthy elderly after a 12-week exercise program based on aerobic and strengthening exercises. In addition to the fact that the present study had a different design from Meijer's study, we could hypothesize that the conflicting results are attributed to the higher time of participation in exercise programs in our study (12 months, in general). Very interestingly, PG had higher number of steps/day even in the days when there was no participation in the exercise program, what demonstrates that subjects in the PG assimilated a more active lifestyle and translated it into being more active every single day.

The proportion of elderly in PG classified as physically active was twice the observed in NPG ( $37 \%$ vs. $16 \%$ ), whereas the proportion of sedentary elderly was much higher in NPG (33\% vs. 14\%) ( $\mathrm{p}<0.001$, for all). According to Tudor-Locke et al. ${ }^{9}$, 8000 steps/day is a good estimation of $30 \mathrm{~min}$ of daily moderate-intensity activities which is the current recommendation for one being considered physically active $^{19}$. Aoyagi and Shephard ${ }^{20}$ showed that a better overall health is seen in elderly individuals who take an average of $>8000$ steps/day. Thus, a considerable number of physically independent elderly in PG are achieving the minimum daily amount of physical activity necessary to promote and maintain health. Furthermore, a higher level of physical activity is associated with a reduced risk of death as recently demonstrated by Hrobonova et al. ${ }^{4}$ in a longitudinal study with 1449 community dwelling older people.

Additionally, we showed that in PG there was no difference between the median steps/day during days with or without participation in the exercise program. This result once again confirmed that participation in a community-based exercise program could positively change the lifestyle of physically independent elderly's daily life. In contrast, Washburn and Ficker ${ }^{21}$ and Meijer et al. ${ }^{1}$ found difference in the level of PADL between exercise and non-exercise program days of older people enrolled in exercise programs. 
The different conclusions demonstrated by those authors could be attributed to some methodological issues observed in those studies such as small sample size (18 participants ${ }^{21}$ and 15 participants ${ }^{1}$ ), shortterm exercise training ( 12 weeks $\left.{ }^{1}\right)$, reduced number of days of PADL assessment (3 days) and assessment of PADL occurring during only one season (October and November $)^{21}$ which is known to influencing the PADL level.

We also found that $56 \%$ of the variability in the level of PADL in physically independent elderly was explained by participation in community-based exercise programs, maximal and functional exercise capacity. In the same way, Ashe et al. ${ }^{22}$ demonstrated that mobility, body mass index, age and impact of living with chronic disease were determinants of mean daily pedometer steps in older people; however, it could explain only $27 \%$ of the level of PADL. Our findings confirmed the importance of older people being engaged in exercise programs developed especially for that population and maintain appropriate levels the maximal and functional exercise capacity.

Some age-related disorders such as cardiovascular and musculoskeletal diseases were observed in the group of elderly individuals studied. However, the prevalence of diabetes mellitus and peripheral vascular disease were lower among those who were participants in community-based exercise programs. Park et al. ${ }^{23}$ demonstrated that older people aged 65-74 years who take $>10000$ steps/day had lower risk of hyperglycemia; in those aged 75-84 years, the corresponding threshold was $>8000$ steps/day. It could explain the difference found in our results since the proportion of physically independent elderly with median of steps per day higher than 10000 was higher in PG in comparison to NPG (26\% vs. $14 \%, \mathrm{p}=0.017)$.

Elderly who were participants in exercise programs, besides having a higher level of PADL, presented better maximal and functional exercise capacity in comparison to those who were not participants. Moreover, they had a higher lower limb muscle strength, agility and static balance. These results were expected because of the exercise programs structure, which included aerobic, strength and balance exercises. Nevertheless, the better physical and functional condition of PG may certainly help these individuals when facing the difficulties generally presented by the aging process. The similarity between the two groups in hand-grip strength and flexibility can be explained by way of use and training of these capacities. The decrease in strength of upper limbs in aging is slower than that of lower limbs ${ }^{24}$. This difference is partly explained by increased utilization of upper limbs muscle groups during household and daily activities in genera ${ }^{25}$. On the other hand, the similarity in flexibility between PG and NPG groups could be attributed to the fact that exercise programs assessed in the present study did not focus on this ability.

Despite the present results demonstrating the importance of community-based exercise programs in influencing the level of PADL of physically independent elderly, some limitations were observed in our study. Firstly, as it was a cross-sectional study, we could not confirm whether participation in community-based exercise programs was a cause or a consequence of the level of PADL. Secondly, we used pedometers as the instrument to assess PADL instead of accelerometers which are more accurate, especially when assessing people who present a lower walking speed such as elderly. However, Harris et al. ${ }^{26}$ previously have shown a good correlation between pedometer step count and accelerometer activity count in physically independent elderly $(r=0.82$, $\mathrm{p}<0.001$ ) which supports the use of pedometers for assessing PADL level in our study. In addition, eventual assessment inaccuracy which might occur in some individual subjects may be considerably reduced in a group basis. Moreover, we checked the presence of comorbidities using a self-reported questionnaire which limited the information about the health status of the elderly. Finally, the various elderly subjects who took part in the communitybased exercise programs did not have the same time of participation in the respective program. In addition, we included participants from five different programs and this could influence the results; however, our aim was to evaluate community-based exercise programs in general instead of evaluating the effects of any specific program. Despite the limitations listed above, authors were cautious when recruiting healthy elderly non-participants in community-based exercise programs from the same regions of the city to ensure that socio-demographic factors could not influence the level of PADL.

\section{Conclusion}

In physically independent elderly, a higher level of physical activity in daily life was found in those who participate in community-based exercise programs, regardless of the weekday and including non-program days. Participation of elderly in community-based exercise programs should be more systematically facilitated and encouraged due to its close link to higher activity levels and better exercise capacity. 


\section{Acknowledgements}

The all investigators involved in data collection for this study.

\section{References}

1. Meijer EP, Westerterp KR, Verstappen FT. Effect of exercise training on total daily physical activity in elderly humans. Eur J Appl Physiol Occup Physiol. 1999;80(1):16-21.

2. Paterson DH, Jones GR, Rice CL. Ageing and physical activity: evidence to develop exercise recommendations for older adults. Can J Public Health. 2007;98 Suppl 2:S69-108

3. Belza B, Shumway-Cook A, Phelan EA, Williams B, Snyder SJ, LoGerfo JP. The effects of a communitybased exercise program on function and health in older adults: The EnhanceFitness Program. J ApplGerontol. 2006;25(4):291-306.

4. Hrobonova E, Breeze E, Fletcher AE. Higher levels and intensity of physical activity are associated with reduced mortality among community dwelling older people. J Aging Res. 2011;2011:651931. http://dx.doi. org/10.4061/2011/651931

5. Spirduso WW, Cronin DL. Exercise dose-response effects on quality of life and independent living in older adults. Med Sci Sports Exerc. 2001;33(6 Suppl):S598-608; discussion S609-10.

6. Alburquerque-Sendín F, Barberio-Mariano E, BrandãoSantana N, Rebelatto DAN, Rebelatto JR. Effects of an adapted physical activity program on the physical condition of elderly women: an analysis of efficiency. Rev Bras Fisioter. 2012;16(4):328-36. Epub 2012 Jun 14.

7. World Health Organization. Active aging: a policy framework. Available at: http://www.who.int/ageing/ publications/active/en/index.html. Accessed on May, 2011.

8. Tudor-Locke C, Bassett DR Jr. How many steps/day are enough? Preliminary pedometer indices for public health. Sports Med. 2004;34(1):1-8.

9. Tudor-Locke C, Leonardi C, Johnson WD, Katzmarzyk PT, Church TS. Accelerometer steps/day translation of moderate-to-vigorous activity. Prev Med. 2011;53(1-2):31-3. Epub 2011 Feb 2.

10. American Thoracic Society. ATS statement: guidelines for the six-minute walk test. Am J Respir Crit Care Med. 2002;166(1):111-7.

11. Troosters T, Gosselink R, Decramer M. Six minute walking distance in healthy elderly subjects. Eur Respir J. 1999;14(2):270-4.

12. Singh SJ, Morgan MD, Scott S, Walters D, Hardman AE. Development of a shuttle walking test of disability in patients with chronic airways obstruction. Thorax. 1992;47(12):1019-24.

13. Vianna LC, Oliveira RB, Araujo CG. Age-related decline in handgrip strength differs according to gender. J Strength Cond Res. 2007;21(4):1310-4.
14. Mathiowetz V, Kashman N, Volland G, Weber K, Dowe M, Rogers S. Grip and pinch strength: normative data for adults. Arch Phys Med Rehabil. 1985;66(2):69-74.

15. Lemmink KA, Kemper HC, de Greef MH, Rispens P, Stevens M. The validity of the sit-and-reach test and the modified sit-and-reach test in middle-aged to older men and women. Res Q Exerc Sport. 2003;74(3):331-6.

16. Jones CJ, Rikli RE, Beam WC. A 30-s chair-stand test as a measure of lower body strength in community-residing older adults. Res Q Exerc Sport. 1999;70(2):113-9.

17. Osness WH, Adrian M, Clark B, Hoeger W, Raab D, Wiswell R. Funtional fitness assessment for adults over 60 years. American Alliance for Health, Physical Education, Recreation and Dance: Reston; 1990.

18. Greene LS, Williams GH, Macera CA, Carter JS. Identifying dimensions of physical (motor) functionalcapacity in healthy older adults. J Aging Health.1993;5(2):163-78.

19. Haskell WL, Lee IM, Pate RR, Powell KE, Blair SN, Franklin BA, et al. Physical activity and public health: updated recommendation for adults from the American College of Sports Medicine and the American Heart Association. Med Sci Sports Exerc. 2007;39(8):1423-34.

20. Aoyagi Y, Shephard RJ. Steps per day: the road to senior health? Sports Med. 2009;39(6):423-38. http:// dx.doi.org/10.2165/00007256-200939060-00001

21. Washburn RA, Ficker JL. Does participation in a structured high-intensity exercise program influence daily physical activity patterns in older adults? Res Q Exerc Sport.1999;70(2):201-5.

22. Ashe MC, Eng JJ, Miller WC, Soon JA. Disparity between physical capacity and participation in seniors with chronic disease. Med Sci Sports Exerc. 2007;39(7):1139-46.

23. Park S, Park H, Togo F, Watanabe E, Yasunaga A, Yoshiuchi K, et al. Year-long physical activity and metabolic syndrome in older Japanese adults: crosssectional data from the Nakanojo Study. J Gerontol A Biol Sci Med Sci. 2008;63(10):1119-23.

24. American College of Sports Medicine, Chodzko-Zajko WJ, Proctor DN, Fiatarone Singh MA, Minson CT, Nigg $\mathrm{CR}$, et al. American College of Sports Medicine position stand. Exercise and physical activity for older adults. Med Sci Sports Exerc. 2009;41(7):1510-30.

25. De Zwart BC, Frings-Dresen MH, van Dijk FJ. Physical workload and the aging worker: a review of the literature. Int Arch Occup Environ Health. 1995;68(1):1-12.

26. Harris TJ, Owen CG, Victor CR, Adams R, Ekelund U, Cook DG. A comparison of questionnaire, accelerometer, and pedometer: measures in older people. Med Sci Sports Exerc. 2009;41(7):1392-402.

\section{Correspondence}

Nidia A. Hernandes

Rua Montese, 149, ap. 502,

Jd. Higienópolis

CEP 86015-020, Londrina, PR, Brasil

e-mail: nyhernandes@gmail.com 